\title{
Justiça ecológica como bússola para ações em favor da agricultura urbana e periurbana
}

\section{Ecological justice as a compass for actions in favor of urban and peri-urban agriculture}

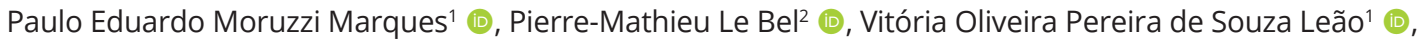
Roberta Moraes Curan'1 (D)

\footnotetext{
${ }^{1}$ Escola Superior de Agricultura "Luiz de Queiroz", Programa de Pós-graduação Interunidade em Ecologia Aplicada, Universidade de São Paulo (USP), Piracicaba (SP), Brasil. E-mail: pmarques@usp.br, vitorialeao.usp@gmail.com, ro.curan@gmail.com ${ }^{2}$ Centre de Recherche d'Etude de Formation à l'Animation et au Développement (CREFAD), Clermont-Ferrand, França. E-mail: pmlebel@gmail.com
}

Como citar: Moruzzi Marques, P. E., Le Bel, P., Leão, V. O. P. S., Curan, R. M. (2021). Justiça ecológica como bússola para ações em favor da agricultura urbana e periurbana. Revista de Economia e Sociologia Rural, 59(4), e239176. https://doi. org/10.1590/1806-9479.2021.239176

\begin{abstract}
Resumo: Este artigo explora a teoria das justificações para a análise das motivações e estratégias de atores da Agricultura Urbana e Periurbana (AUP) no estado de São Paulo, considerando perspectivas de desenvolvimento de seus territórios. Com uma abordagem cruzando sociologia e geografia, a pesquisa que ofereceu elementos de análise para a elaboração deste artigo fundamentou-se em entrevistas semiestruturadas, observações de campo e análise documental, considerando os casos do assentamento Milton Santos, situado parte em Americana, parte em Cosmópolis, assim como da Associação de Agricultores da Zona Leste da capital. O direito de acesso ao fundiário é absolutamente central para a AUP. A reivindicação deste direito, bem como a concepção de papéis das atividades compreendidas pela AUP, mobilizam referências de justiça com contornos ecológicos, o que oferece crescente legitimidade à causa, gerando diversos tipos de apoios. Porém, as evidências dos casos estudados indicam que a AUP está longe de ter sua perenidade e crescimento assegurados.
\end{abstract}

Palavras chave: produção alimentar local, teoria das justificações, desenvolvimento territorial, circuitos curtos alimentares, sustentabilidade.

\begin{abstract}
This article explores the theory of justifications for the analysis of the motivations and strategies of actors in urban and peri-urban agriculture (UPA) in the state of São Paulo, considering perspectives for the development of their territories. With an approach crossing sociology and geography, the research which subsidized the elements brought to analysis in this article was based on a semi-structured interview, field observation, and documental analysis, considering the Milton Santos settlement in Americana and Cosmópolis and the Zona Leste Farmers Association in São Paulo city. The right of land access is central to the UPA. The claiming of this right, as well as the conception of the roles played by the practices concerning UPA, mobilize references of justice with ecological outlines, which offers increasing legitimacy to the cause, generating various types of support. However, the evidences of the studied cases point out that UPA is far from having a recognition that would ensure its perpetuity and growth.
\end{abstract}

Keywords: local food production; Theory of justifications; Territorial development; Short food supply chains; Sustainability.

\section{Introdução}

Diferentes contribuições destacam o papel do alimento como interface entre políticas públicas e iniciativas cidadãs (Morgan, 2009; Lardon et al., 2017), assim como campo de ação transversal no qual se encontram múltiplas competências públicas, tais como saúde, educação, meio ambiente, agricultura, entre outras (Wiskerke, 2010; Lamine et al., 2012). O problema alimentar está no cerne do campo de pesquisa sobre a Agricultura Urbana e Periurbana (AUP), que se revela muito dinâmico em razão da constatação de sua evidente imbricação com os 
desafios ambientais, econômicos, sociais e de saúde pública (Guiraud et al., 2014; Thompson \& Scoones, 2009).

Neste âmbito, a governança da AUP constitui uma questão central para seu desenvolvimento, associada à participação social na gestão complexa de sistemas logísticos e agronômicos que, via de regra, são pouco transparentes e reservados a atores do mercado e do Estado (Moragues-Faus, 2017). Os desafios em torno desta participação se vinculam igualmente à articulação entre diferentes escalas de ação. Com efeito, a governança da produção agrícola e do desenvolvimento sustentável pressupõe a consideração de questões transversais para estabelecer estratégias consistentes, além de permitir adequadamente monitorar ações com vistas a uma agricultura sustentável (Wald \& Hill, 2015).

Esta transversalidade é coerente com a perspectiva de desenvolvimento territorial, enquanto princípio de ação pública bastante difundido a partir dos anos 1990. Fortemente impulsionada pelas reflexões sobre o desenvolvimento local, a perspectiva em questão visa uma mudança de abordagem, visto que antes de ter um engajamento em torno de teorias específicas a cada cadeia de produção e atividade, trata-se de considerar o próprio território como espaço de florescimento de múltiplas potencialidades que Ihe são inerentes. A oposição dos termos vertical (top-down) e horizontal (bottom-up) permite tomar em conta as modificações em questão. Assim, o desenvolvimento territorial é concebido como um processo horizontal, na medida em que tende a favorecer a participação de um amplo leque de atores (especialistas, moradores locais, usuários de serviços, empresários, representantes de Organizações Não Governamentais e dos poderes públicos). Nesta ótica, constitui uma "estratégia coletiva" (Greffe, 2002, p. 97), que pode ser definida como processo sustentável de construção e de gestão de um território pelo qual sua população, por meio de pacto sociopolítico e de quadro institucional apropriado, define sua relação com a natureza, estabelece seu modo de vida, consolida seus laços sociais, aprimora seu bem-estar e constrói uma identidade cultural territorial (Peemans, 2008, p. 31).

A mobilização do termo território neste artigo fundamentou-se em concepção segundo a qual constitui expressão espacial das relações de força não limitada à ação do Estado, mas se estendendo por meio de um conjunto de atores a partir de ideias, materiais e componentes organizacionais. Trata-se de uma conceituação de território associada às perspectivas de autores como David Harvey (2005) ou Manuel Castells (1974), mas também de geógrafos e sociólogos franceses que influenciaram notadamente Milton Santos, como Henri Lefebvre (1974), Yves Lacoste (1976), Pierre Georges (1981) e Claude Raffestin (1993). Embora a concepção de território tenha se enriquecido em Santos, permanece neste autor a perspectiva de um espaço de relações de força (Santos, 1994; Dematteis, 2005). Nesta contribuição, estas últimas são visíveis tanto nas tensões entre ações públicas e atores locais quanto entre distintos projetos com justificações ancoradas em diferentes regimes de justiça.

A perspectiva de desenvolvimento territorial abre portas para atores reivindicarem maior participação na governança da produção alimentar urbana e periurbana (Trauger, 2015). Neste campo, uma análise sobre os princípios de justiça que motivam suas ações parece bastante pertinente. Assim, a contribuição deste artigo consiste em evidenciar as bases das argumentações dos atores da AUP em termos de acesso ao solo, de apoio público a suas iniciativas e de seu papel no desenvolvimento. A imbricação da agricultura no espaço urbano supõe a elaboração de discursos de justificação com diferentes ênfases. Então, trata-se de interrogar os modos de construção de legitimidade das causas defendidas pelos atores implicados na AUP. O interesse pela análise das motivações não se limita a estabelecer um simples retrato de situações, mas também permite distinguir registros de justificação que podem evidenciar pontos de bloqueio e oportunidades de alianças. 
A pesquisa realizada se situa no encontro entre a sociologia e a geografia. Os espaços de AUP podem ser assim considerados como "objetos espaciais integradores", tal como proposto por Lardon et al. (2017). Estes autores consideram o alimento como objeto espacial integrador que está posicionado na interseção da produção agrícola, da mercadoria e de projetos coletivos. Esta característica o torna capaz de aglutinar ações em torno do desenvolvimento territorial. Os objetos são designados como integradores quando possuem uma capacidade de reunir múltiplos e variados atores em torno dos desafios que Ihes perpassam. Assim, através destes objetos “os atores se apropriam de uma visão prospectiva do território" (Lardon et al., 2016, p. 275).

Associado à produção do alimento, o potencial integrador da AUP levanta a questão do alinhamento de registros de justificação mobilizados pelos atores de índoles diversas (associativa, política, empresarial) sobre um mesmo eixo. Deste modo, convém discutir em que medida tais atores adotam posturas e praticam ações, mesmo que temporárias, mas com objetivos comuns. Nesta perspectiva, a abordagem teórica da sociologia das justificações constitui uma base interpretativa fecunda para nosso estudo (Boltanski \& Thévenot, 1991), oferecendo sólidas referências para tratar de acordos e desavenças no espaço público.

Com este referencial analítico, a pesquisa que originou este artigo focalizou os casos do assentamento Milton Santos, situado parte em Americana, parte em Cosmópolis, bem como da Associação de Agricultores da Zona Leste da capital, representando relevantes realidades de AUP. A metodologia de coleta de dados teve caráter qualitativo, combinando observação participante, entrevistas e análise documental. Notadamente, foram consultados o Plano Diretor de Desenvolvimento Físico Urbanístico do município de Americana ${ }^{1}$ e o Plano Diretor Estratégico (PDE) do município de São Paulo². A pesquisa de campo foi realizada em novembro de 2019 e contou com cinco entrevistas semiestruturadas junto a dirigentes de coletivos das AUP consideradas, a representantes dos poderes públicos e a membros de organizações de apoio da sociedade civil. Essas pessoas entrevistadas foram convidadas a formular seus parâmetros e significações em torno de seu engajamento em AUP (McCarthy \& Zald, 1977; Tilly \& Tarrow, 2008). O foco se dirigiu aos objetivos dos atores, aos princípios de justiça que fundamentam suas reivindicações e às grandes orientações exprimidas, assim como à participação na governança da AUP e, enfim, aos obstáculos encontrados por seus principais protagonistas.

Por outro lado, a agricultura urbana da Zona Leste de São Paulo e o assentamento Milton Santos são focalizados em estudos realizados pelos autores deste artigo desde 2010. No primeiro caso, a experiência de constituição de Organizações de Controle Social (OCS) foi analisada enquanto dispositivo que favorece relações mais sólidas de confiança entre produtores e consumidores (Leão, 2019), assim como os múltiplos papéis desta agricultura foram evidenciados (Curan, 2020). No segundo caso, as pesquisas se referiram notadamente aos impactos socioambientais da implantação do assentamento (Moruzzi Marques et al., 2014), aos efeitos da participação em programas públicos agroalimentares (Moruzzi Marques \& Moal, 2014) e à evolução ao longo do tempo dos regimes de justiça mobilizados para justificar as ações das famílias assentadas (Moruzzi Marques et al., 2016; Moruzzi Marques et al., 2017; Retière \& Moruzzi Marques, 2019).

No que se refere à justificação de escolha destes campos de estudo, a cidade de São Paulo oferece um quadro de numerosas iniciativas de agricultura urbana. Estas experiências passaram a ter mais visibilidade com o reconhecimento relativo, por parte de atores públicos, do papel da atividade agrícola urbana para a geração de renda e para a melhoria da qualidade de vida na cidade. A recente delimitação da zona rural do município de São Paulo, resultado

1 Lei $n^{\circ} 6.264$, de 21 de dezembro de 2018.

2 Lei $n^{\circ} 16.050$, de 31 de julho de 2014. 
da revisão de seu PDE em 2014, permitiu a elaboração do Plano Municipal de Agroecologia e Desenvolvimento Rural Sustentável e Solidário (PMADRSS), uma das diretrizes previstas em seus propósitos ambientais. Dentre outras repercussões, o referido plano inseriu os debates sobre a AUP na agenda política da cidade.

O outro local de estudo situa-se a cerca de $120 \mathrm{~km}$ da capital, constituindo igualmente um caso interessante para a pesquisa na medida em que ocorreu em 2005 o assentamento, denominado Milton Santos, de famílias sem terra em território periurbano graças à ação do Movimento dos Trabalhadores Rurais Sem Terra (MST). Desde sua instalação, as famílias assentadas procuram escoar seus produtos alimentares por meio de circuitos curtos de comercialização, conhecendo dificuldades crescentes. Contudo, este espaço agrícola periurbano encontra-se ameaçado pelas intenções de expansão urbana, que estão expressas no debate sobre as regulamentações do novo plano diretor do município.

Neste artigo, são apresentados em sua primeira parte pontos pertinentes para caracterizar a AUP, seguida por uma seção sobre o quadro teórico mobilizado para as interpretações, focalizando especialmente elementos centrais da teoria das justificações. Posteriormente, os territórios em estudo são descritos, destacando o lugar da agricultura urbana e periurbana, bem como as iniciativas realizadas em seu favor e os bloqueios para seu desenvolvimento. A última parte do artigo veicula as análises sobre os discursos dos atores, salientando seus valores, suas estratégias e suas críticas, considerando particularmente suas perspectivas de desenvolvimento territorial.

\section{A agricultura urbana e periurbana}

Entre as diversas maneiras de definir a AUP, para os objetivos deste estudo, destacam-se as proposições de Mougeot (2000) e Santandreu \& Lovo (2007) que a caracterizam como uma agricultura integrada no sistema econômico e ecológico da cidade. De fato, sua existência é um fenômeno tão antigo como a própria cidade (Capel, 2002), sendo fortemente ligada a objetivos de autossuficiência alimentar (Pessoa et al., 2006; Neves et al., 2010), mas reconhecidamente com um caráter multifuncional (Nahmias \& Le Caro, 2012). Esta constatação sugere que a AUP não deva ser considerada em compartimentos estanques, mas leva a inscrevê-la em lógicas integradoras de desenvolvimento territorial.

Em princípio, a AUP refere-se ao cultivo de plantas e à criação de animais no espaço urbano, à prática agrícola de citadinos, à utilização de resíduos orgânicos, à reutilização da água de irrigação e à proximidade do mercado consumidor (Resources Centres on Urban Agriculture \& Food Security Foundation, 2018). É oportuno notar que as atividades da agricultura urbana podem ser praticadas em interstícios com diferentes tamanhos do tecido urbano (Madaleno, 2002). A Organização das Nações Unidas para a Agricultura e a Alimentação (em inglês Food and Agriculture Organization, FAO) indica que a AUP ocupa majoritariamente espaços de pequena dimensão, podendo se situar em zonas públicas, privadas ou comuns, geralmente na periferia das cidades (Food and Agriculture Organization of the United Nations, 2010). O estudo de Van Veenhuizen (2006) permite completar esta caracterização da FAO, apresentando a AUP como fonte de alimentos perecíveis, como legumes e verduras, além de ser essencial aos sistemas alimentares regionais e nacionais. A propósito, Opitz et al. (2015) sugeriram que a agricultura periurbana cumpre um papel notável no abastecimento das cidades, em razão, sobretudo, de representar uma maior disponibilidade de terras agricultáveis.

No Brasil, a AUP foi integrada pela primeira vez em 2004 em uma proposta de política pública na Conferência Nacional de Segurança Alimentar e Nutricional (CNSAN). A partir de então, foram 
concebidos dispositivos voltados ao levantamento de iniciativas anteriormente existentes e à promoção da prática a nível nacional. No entanto, as ações sofreram descontinuidade com as mudanças de gestão do Programa de Agricultura Urbana do Ministério do Desenvolvimento Social (MDS). Desta maneira, este apoio depende de iniciativas da sociedade civil organizada ou de políticas limitadas ao âmbito municipal (Biazoti, 2020; Giacchè 2015).

A propósito, Santandreu \& Lovo (2007) detectaram uma diversidade de tipos de AUP no Brasil, desde quintais domésticos até vastas áreas de produção em regiões periurbanas. A respeito da heterogeneidade de experiências de AUP, Mougeot (2000) pôde destacar a importância da relação urbano-rural na concepção de políticas públicas adequadas, uma vez que as interações destas atividades agrícolas ocorrem não apenas com os sistemas urbanos, mas também com a produção rural alimentar (Chiaramonte Pires, 2016). Neste ponto, torna-se oportuno mencionar o argumento de Travassos \& Portes (2018) segundo o qual as zonas rurais persistentes nas metrópoles brasileiras são praticamente invisíveis no âmbito das políticas públicas. Os autores realçaram que tais perímetros têm sido tratados costumeiramente como estoque de terras para urbanização.

De toda maneira, a AUP promove diferentes dinâmicas e arranjos nos territórios urbanos e periurbanos. Suas características, sob uma perspectiva territorial, permitem transcender a dicotomia urbano-rural, rompendo com papéis tradicionalmente atribuídos a esses dois universos (Favareto, 2007).

Assim, a AUP envolve dinâmicas que se situam muito além das técnicas agrícolas e urbanísticas, inscrevendo-se em transformações sociais que transcendem disciplinas estanques. Com efeito, a AUP leva a questionamentos das relações de força no território, provocando novos arranjos de atores (Gottlieb \& Joshi, 2010) e influenciando estratégias de desenvolvimento territorial de longo prazo (Kay et al., 2018).

Entre as transformações sociais em torno da AUP, apresenta relevância a busca pela equidade de gênero. Considerando os poucos trabalhos sobre esta questão, apesar do protagonismo das mulheres na prática da AUP, foi criado um grupo de estudo intitulado "Mulheres e Agroecologia", no âmbito do Conselho Municipal de Desenvolvimento Rural Sustentável e Solidário (CMDRSS) do município de São Paulo. Este grupo em parceria com a organização não governamental Sempreviva Organização Feminista (SOF) tem como intuito a constituição de uma rede de envolvidas nas atividades de AUP no município, para que haja o fortalecimento do movimento (Carvalho \& Bógus, 2020).

Enfim, de certa maneira, este artigo pôde explorar com mais profundidade os elementos de sentido tratados por Caldas \& Jayo (2019), que se interessaram pelos significados atribuídos pelos atores a suas práticas. Todavia, estes autores não consideraram estes sentidos como conjugados a regimes mais globais de justificação da ação, o que é propósito deste artigo.

\section{A teoria das justificações}

Para realizar a análise dos discursos dos atores da AUP, com interesse em identificar suas motivações e capacidades de canalizar reivindicações para a esfera pública de tomada de decisão, a teoria das justificações (Boltanski, 1990; Boltanski \& Thévenot, 1991; Moruzzi Marques, 2014) constitui uma abordagem muito apropriada. Trata-se de modelo fecundo para identificação de referências de justiça mobilizadas na formulação de argumentos por atores implicados em determinado campo de produção de ideias. Agrupados em conjuntos coerentes de normas para edificar um mundo concebido como justo, estes princípios de justiça são capazes de sustentar a construção de justificações para a defesa ou a crítica de uma causa, bem como para 
a articulação de demandas e para a elaboração de estratégias. Em outras palavras, torna-se possível situar os discursos, os acordos e os desacordos em repertório contendo diferentes maneiras de conceber uma sociedade justa.

Nesta ótica, o sucesso de uma operação de justificação depende da capacidade do ator em generalizar, ligando seu caso individual aos interesses de um coletivo, de modo a articular propriedades específicas locais com princípios de justiça com caráter universal. Estas referências para o alcance de um mundo justo são inscritas num repertório de "cités", ou seja, diferentes regimes de justiça cuja legitimidade varia em função de diferentes contextos socio-históricos.

Em obra referencial da teoria das justificações, Boltanski \& Thévenot (1991) identificaram seis regimes de justiça: inspirada; do renome; doméstica; cívica; industrial e mercantil. Trata-se tanto de conjuntos de referências para se alcançar um mundo justo, com coerência argumentativa interna a partir de determinada visão de mundo, quanto de orientações para atingir tal estado de justiça. Ao longo dos últimos anos, outros autores propõem a inclusão neste repertório de um regime ecológico de justiça (Lafaye \& Thévenot, 1993; Latour, 1995; Van Dam \& Nizet, 2012; Retière \& Moruzzi Marques, 2019).

A ordem inspirada de justiça fundamenta-se na valorização de um ideal transcendental de mundo justo (que pode encontrar eco na espiritualidade ou na abstração artística). A "cidade de Deus" de Santo Agostinho é notadamente explorada por Boltanski \& Thévenot (1991) por descrever esta " cité". No caso da ordem do renome, as referências de justiça estão associadas à visibilidade e à popularidade de personalidades susceptíveis de propor soluções justas. As influências dos gostos e sugestões de celebridades midiáticas podem ilustrar as prevalências neste regime de justiça.

O regime doméstico repousa sobre a ideia segundo a qual é a posição do indivíduo nas linhas das relações interpessoais que determina seu valor. O indivíduo superior deve proteção e justiça aos seus subordinados que, por sua vez, devem se submeter a esta dependência, oferecendo seus serviços e sua fidelidade ao rei, governador ou patrão, em relações tipicamente paternalistas. Com efeito, as lógicas das relações familiares patriarcais são transpostas para a concepção de uma sociedade justa. Neste âmbito, a tradição, a proximidade, a especificidade e a confiança são muito valorizadas, mas nem sempre de maneira associada às lógicas de dependência.

$\mathrm{Na}$ ordem cívica justa, a autoridade se constitui a partir da convergência das vontades humanas. A participação no espaço público para realizar o bem comum acima dos interesses individuais é altamente apreciada aqui. A hierarquia dos indivíduos estabelece-se em função da capacidade de participação em causas públicas, visando alcançar o desejo coletivo com desapego ao interesse particular.

Os fundamentos dos regimes de justiça industrial e mercantil contam, na sociedade capitalista contemporânea, com grande legitimidade no debate público. De uma parte, a ordem industrial fundamenta-se na concepção segundo a qual uma sociedade justa funciona como uma máquina de produção eficaz. Sua hierarquia de valores repousa sobre a utilidade social dos indivíduos no processo produtivo. De outra parte, o regime mercantil sobrevaloriza as relações de mercado, tornando a capacidade de acumulação de riqueza a peça central de sua hierarquia de poder e prestígio. Desta maneira, o valor do indivíduo é proporcional à sua riqueza e ao seu consumo. Por fim, as relações comerciais são vistas como apaziguadoras, canalizando as paixões para a concorrência "saudável" do mercado.

Embora haja uma pretensão de universalidade, cada diferente concepção de mundo justo conhece uma aceitação e uma validade variável conforme os contextos socio-históricos e as

3 O termo "cite" é empregado por Boltanski e Thévenot (1991) para associar os ordenamentos de justiça com um espaço comum de convivência no qual os atores manifestam publicamente suas aspirações, permitindo lembrar a polis da Grécia antiga. 
diversas situações de desacordo. Nesta medida, torna-se pertinente considerar que estas ordens de justiça podem mudar, o que supõe a possibilidade de emergência de novas formas de ordenar um mundo justo. Nesta linha de raciocínio, a proposta de considerar que emerge um regime ecológico de justiça ganha consistência na reflexão sobre a teoria das justificações. Com efeito, o debate sobre os impactos ambientais degradantes em razão das atividades humanas conhece uma legitimidade crescente desde notadamente os anos 1990. As proposições em favor de um desenvolvimento sustentável se multiplicam como horizonte desejável para guiar as dinâmicas sociais, econômicas e políticas. Apesar de contornos em construção, é possível considerar que a "cité" ecológica privilegia a autonomia e a simplicidade. A dimensão espacial preferida é a escala local, bem que sempre associada aos desafios globais. O longo prazo é privilegiado em termos de dimensão temporal, como evidenciam as referências recorrentes às gerações futuras no debate sobre a sustentabilidade (Van Dam \& Nizet, 2012).

Por fim, é importante conceber estes regimes de justificação sem que haja uma hegemonia absoluta de um em relação aos outros, em determinados períodos ou situações. De fato, os elementos destes conjuntos dinâmicos se entrelaçam, mesmo que um regime possa contar com uma predominância em dada civilização. É tal perspectiva que torna a abordagem da teoria das justificações instigante para a análise das relações entre atores diferentes. Com efeito, o estudo destes entrelaçamentos pode iluminar pontos de aproximação de ambições e estratégias, que a priori podem parecer inconciliáveis, particularmente em termos territoriais (Sanchez-Hernandez \& Moro-Gutierrez, 2019).

\section{Os casos estudados}

O contexto da ação é fundamental para a análise sobre a maneira pela qual os indivíduos formulam seus argumentos em debates públicos, tal como salienta Jacquemain (2001). Convém igualmente aqui realçar a equação explicativa das ações humanas proposta por Bernard Lahire (2013), com a qual o autor insiste sobre o papel também crucial dos processos socializadores do passado. Lahire considera que as manifestações humanas são um resultado do cruzamento, de uma parte, das disposições incorporadas ao longo da vida e, de outra parte, dos constrangimentos do contexto. Com esta ótica, nesta parte do artigo, destacamse as situações concretas específicas nas quais se constroem os discursos de atores da AUP.

Em relação às entrevistas, a escolha recaiu sobre atores fortemente engajados com a pauta da AUP em âmbito local. Os eixos de conteúdo considerados nas entrevistas semiestruturadas foram os seguintes: desafios e problemáticas do território urbano e periurbano; projetos de AUP e seus bloqueios; políticas de desenvolvimento territorial e/ou sustentável. Em São Paulo, as entrevistas foram realizadas com uma profissional da Secretaria Municipal de Urbanismo e Licenciamento, uma liderança da Associação dos Agricultores da Zona Leste (AAZL) e uma representante da sociedade civil organizada. Em Americana, as entrevistadas foram efetuadas com uma vereadora com atuação no assentamento Milton Santos e uma liderança local das famílias assentadas. Vale mencionar que as informações obtidas nas entrevistas foram enriquecidas por meio de observação participante dos autores.

\subsection{O caso da agricultura urbana de São Paulo}

Muitas iniciativas associativas em torno da AUP ocorrem no município de São Paulo, como é o caso das Cidades Comestíveis. Trata-se de uma plataforma digital a partir da qual os residentes são convidados a trocar conhecimentos sobre alimentos, sementes e todos os recursos 
associados à agricultura e à alimentação. Por outro lado, o Movimento de Agroecologia Urbana de São Paulo (MUDA) constitui uma rede de indivíduos e organizações tendo por objetivo a promoção de agriculturas ecológicas na cidade graças a cursos, ações de sensibilização dos consumidores e formulação de propostas de políticas públicas. Ainda, entre os exemplos selecionados, a União das Hortas Comunitárias de São Paulo agrupa quatorze coletivos de horticultores do município com o objetivo de promover troca de experiências e de reforçar a agricultura urbana paulistana.

Na esfera governamental, questões sobre a agricultura urbana passaram a ocupar um lugar importante desde o início dos anos 2000. Em 2006, foram criadas em São Paulo as Casas de Agricultura Ecológica (CAEs) a fim de fornecer apoios diversos à produção e comercialização da AUP visando sua sustentabilidade. Em 2014, no contexto da revisão do PDE de São Paulo, um perímetro rural foi delimitado na Zona Sul do município, na qual a agricultura é concebida como uma atividade que desempenha um papel importante para o desenvolvimento sustentável. Em 2016, o projeto "Ligue os Pontos" no âmbito da Secretaria Municipal de Desenvolvimento Urbano (SMDU) foi implantado com o objetivo de impulsionar a agricultura na referida zona rural do município para que possa gerar renda para a população, transformando a região em polo de sustentabilidade. Para tal propósito, é destacada a pertinência da integração de diferentes políticas setoriais, com o envolvimento de distintas secretarias e órgãos da administração municipal.

O abastecimento da alimentação escolar evoluiu igualmente para o favorecimento da agricultura familiar local, graças às normativas nacionais encampadas pela administração municipal com vistas ao fornecimento alimentar em circuitos curtos. Com efeito, desde 2009, o Programa Nacional de Alimentação Escolar (PNAE) exige que ao menos 30\% de seus recursos repassados às entidades executoras pelo Fundo Nacional de Desenvolvimento da Educação (FNDE) sejam destinados à aquisição direta de alimentos dos agricultores familiares.

Como já mencionado, foi analisado aqui o caso da AAZL. Em 2019, esta associação contava com aproximadamente 30 membros, reunindo-se mensalmente para manter a coesão do grupo e tratar de suas ações. Apesar de variações frequentes no número de associados, a AAZL é formada por um núcleo central constituído de 16 hortas que abrigam agricultores que participam mais intensamente de feiras, de suas reuniões e de eventos promovidos na cidade. Criada em 2009 graças a uma importante mobilização de agricultores urbanos, a associação foi apoiada pela subprefeitura de São Mateus.

Quando da elaboração do PDE de 2002, foram identificados muitos indivíduos que, com suas famílias, cultivavam alimentos em terrenos sob linhas de alta tensão ou nas margens de córregos. Foi observado que esta atividade agrícola era acompanhada de troca de material propagativo ou plantas medicinais. De fato, trata-se de uma população com práticas agroalimentares tradicionais, originária de ambientes rurais, sobretudo do interior de São Paulo, do Paraná e do Nordeste.

A partir de 2010, seus cultivos passaram a ter apoio do Programa de Agricultura Urbana e Periurbana do município de São Paulo (PROAURP), permitindo que estes agricultores passassem a ter mais oportunidades para desenvolver suas atividades com maiores perspectivas de gerar renda com relativa autonomia. A formalização da associação e a capacitação dos agricultores para a comercialização receberam o apoio do Serviço Nacional de Aprendizagem Rural (SENAR).

Dentre os diferentes apoios à associação, vale destacar o projeto realizado entre 2015 e 2017 em parceria com o Instituto Kairós, por meio de um edital do Fundo Especial do Meio Ambiente e Desenvolvimento Sustentável (FEMA) da Prefeitura de São Paulo, destinado à obtenção de reconhecimento da produção orgânica local, contando também com a colaboração da Casa 
de Agricultura Ecológica (CAE). Assim, um grupo foi formado no seio da AAZL com agricultores interessados em constituir uma Organização de Controle Social (OCS), dispositivo ratificado pelo Ministério da Agricultura, Pecuária e Abastecimento (MAPA) permitindo reconhecimento da qualidade orgânica a partir de relações de confiança entre produtor e consumidor de forma participativa. Os membros de uma OCS devem autorizar as visitas de consumidores e técnicos do MAPA nas unidades produtivas a fim de poderem verificar os procedimentos técnicos de produção. No entanto, como tal modelo não oferece acesso ao selo de agricultura orgânica, a autorização de comercialização enquanto produto orgânico se limita à venda direta aos consumidores ou às compras públicas, como aquelas destinadas às escolas. Ainda assim, oferece substanciais vantagens, como no caso do fornecimento de alimentação escolar, pois permite que o valor pago aos produtos orgânicos seja acrescido de 30\% em relação ao convencional.

Nas entrevistas, foram elencados diversos problemas destes agricultores, dentre os quais o acesso à terra e à água parece se constituir em obstáculo central para esta agricultura, o que será examinado com mais profundidade a seguir. Quanto aos insumos produtivos, os problemas se referem a uma produção local de composto insuficiente e a espaços de estocagem reduzidos. Ainda foi realçado que a assistência técnica oferecida pela estrutura pública é muito restrita, estando sob responsabilidade de apenas uma profissional o atendimento de toda a Zona Leste paulistana.

\subsection{0 caso da agricultura periurbana do assentamento Milton Santos}

O assentamento Milton Santos situa-se nos municípios de Americana e Cosmópolis, que integram a Região Metropolitana de Campinas no estado de São Paulo. Com uma população próxima a 300.000 habitantes, o território destes dois municípios é marcado por uma intensa urbanização e industrialização, apresentando um espaço rural no qual predomina uma produção canavieira industrial em quadro de forte concentração fundiária.

Em Americana, os poderes executivos e legislativos estavam engajados em 2019 no processo de regulamentação da "Macrozona de Uso Predominante Ambiental" (MPA), cujo território coincide com a Área de Proteção Ambiental Municipal de Americana (APAMAL), o que foi previsto na Lei $n^{\circ} 6.264 / 2018$ que dispõe sobre o Plano Diretor de Desenvolvimento Urbanístico do município. Neste âmbito, predominavam propostas permissíveis à expansão da urbanização desta "macrozona", onde se situa o assentamento Milton Santos.

A implantação deste último é em grande medida fruto de uma reorientação estratégica do MST em favor de práticas agroecológicas. Até meados de 1990, o movimento privilegiava um modelo produtivista para assentamentos situados em territórios rurais predominantemente agrícolas distantes dos grandes centros de consumo (Borsatto \& Carmo, 2013). No início dos anos 2000, uma parte da direção do MST no estado de São Paulo passa a defender a instalação de famílias sem-terra em zonas melhor dotadas em infraestrutura, próximas a grandes aglomerações urbanas, o que foi batizado de "Comunas da Terra". A intenção consistia notadamente em constituir circuitos curtos de comercialização a partir de projetos de produção agroecológica. Com efeito, trata-se de favorecer o engajamento no movimento de famílias empobrecidas residindo em periferias urbanas precárias, considerando a crescente proporção urbana da população paulista.

Após várias tentativas frustradas, um coletivo de famílias sem-terra consegue se estabelecer, com importante apoio de associações e sindicatos urbanos, em terras ocupadas ilegalmente pela Usina Ester com monocultivo industrial canavieiro. No final de 2005, estas famílias foram então assentadas graças à intervenção do Instituto Nacional de Colonização e Reforma Agrária 
(INCRA) em parte destas terras. O INCRA classificou este assentamento como Projeto de Desenvolvimento Sustentável (PDS), o que englobou todas as experiências de Comunas da Terra em São Paulo (Aly Junior, 2011)

Desta forma, 66 famílias foram oficialmente assentadas em 11 de julho de 2006 em área de 103,45 hectares, com o assentamento tendo capacidade de acolher 70 famílias segundo os critérios do INCRA. Os assentados revelam que, no início, eram vistos na vizinhança como oportunistas ou usurpadores. Gradualmente, contudo, esta visão evolui no sentido do reconhecimento do papel destas famílias enquanto atores importantes do abastecimento alimentar local, particularmente em razão do fornecimento pelos agricultores assentados de alimentos aos indivíduos mais vulneráveis graças ao Programa de Aquisição de Alimentos (PAA). Efetivamente, o PAA constituiu por muito tempo o principal meio pelo qual os produtos do assentamento eram comercializados. Ao impulsionar a produção alimentar, este programa contribuiu decisivamente para uma melhora da qualidade de vida das famílias, tanto por gerar renda quanto por promover acesso a uma alimentação diversificada e saudável.

Em 2012, a Usina Ester obteve junto ao Tribunal Regional Federal da $3^{a}$ Região (TFR-3) a reintegração de posse das terras do assentamento, o que provocou grande tensão. Neste afrontamento, as famílias assentadas receberam apoios de diferentes coletivos, entre os quais o Núcleo de Agroecologia Nheengatu da Escola Superior de Agricultura Luiz de Queiroz/ Universidade de São Paulo (ESALQ/USP) e a equipe de agroecologia da Embrapa Meio Ambiente de Jaguariúna. Estes apoios universitários e científicos explicam-se pelas ações locais de docentes, pesquisadores e estudantes com vistas a incorporar práticas agroecológicas na produção de alimentos destinados a famílias sofrendo de insegurança alimentar (Moruzzi Marques et al., 2017). Após meses de grandes incertezas, as famílias assentadas conseguiram uma sentença da justiça permitindo sua permanência no assentamento.

A partir de 2014, a formalização de três OCS permitiu o reconhecimento de qualidade orgânica para grande parte da produção do assentamento. Com a redução drástica do orçamento público destinado ao PAA, sobretudo a partir de 2016, estas OCS constituem um dispositivo que favorece a busca de alternativas, tal como a comercialização de cestas de alimentos orgânicos para grupos de consumo solidário nas redondezas (Mello Pinto \& Moruzzi Marques, 2019). Esta experiência de circuitos curtos alimentares visa maior proximidade entre produtor e consumidor, desenvolvendo-se desde 2015, graças notadamente à implantação de uma cooperativa, Cooperflora. No final de 2019, seis grupos de consumo solidário dos arredores participavam da rede fomentada pela cooperativa.

\section{Ações e concepções de atores da AUP em torno do desenvolvimento territorial}

O repertório de conjuntos de princípios justos proposto no âmbito da teoria das justificações é mobilizado aqui para a análise das argumentações dos atores engajados na agricultura urbana e periurbana. Nesta parte do artigo, o foco dirige-se para as ações e os pontos de vista de atores locais em relação ao desenvolvimento dos territórios em estudo, indicando regimes de justiça que são acionados para a formulação de seus argumentos.

O principal problema em ambos os casos estudados refere-se ao acesso à terra. No caso da cidade de São Paulo, fortes tensões opõem os movimentos de direito à moradia e os grupos de agricultura urbana. Cada polo reivindica, junto ao poder público municipal, acesso à terra com propostas divergentes de ordenamento territorial. A moradia constitui-se em problema crucial e recorrente na maior metrópole da América do Sul. Nestas circunstâncias, os interesses dos promotores imobiliários tendem a influenciar fortemente a tomada de decisão dos poderes 
constituídos no município (Torres et al., 2007). A progressão da expansão urbana irregular ocorre de forma mais rápida do que a implantação de projetos de urbanização da administração municipal, cuja elaboração é muito complicada em razão de negociações envolvendo múltiplos interesses.

Neste contexto de expansão urbana desordenada, a defesa das hortas urbanas concorre com outros discursos e práticas, particularmente aqueles relativos ao direito à moradia. No caso da AAZL, a maior parte dos terrenos ocupados por seus horticultores encontra-se em áreas públicas ou, sob concessão, de empresas que fornecem serviços públicos, como eletricidade (Ente Nazionale per l'Energia Elettrica, ENEL) ou água e esgoto (Companhia de Saneamento Básico do Estado de São Paulo, SABESP). Assim, a ocupação legal destes espaços requer tanto a ratificação de contratos de comodato, quanto o estrito respeito às regras de segurança (por exemplo, observando os cultivos que são autorizados sob os cabos elétricos de alta tensão). No entanto, os entrevistados revelaram que tais contratos existiram no passado, mas hoje estão caducos, o que torna precário o acesso dos agricultores ao solo. Por outro lado, as regras de ocupação destes terrenos são por vezes desconhecidas pelos próprios agentes municipais ou as informações disponíveis neste âmbito são contraditórias. De fato, a ausência de assistência técnica por parte da prefeitura e das empresas concessionárias torna difícil a adoção de práticas que possam ser consideradas adequadas para o uso destes terrenos.

Quanto à formalização desta agricultura urbana, os entrevistados mencionaram muitos obstáculos burocráticos. As dificuldades não apenas se referem ao tempo despendido para efetuar procedimentos administrativos, mas, sobretudo, à linguagem técnica em grande medida incompreensível para os horticultores. Desta maneira, as negociações com os representantes das empresas concessionárias e do poder executivo tendem a ser penosas, envolvendo práticas muito distintas daquelas cotidianas dos agricultores.

Entre os principais riscos enfrentados por estes agricultores urbanos destaca-se a invasão de suas terras por indivíduos em situação de pobreza extrema visando construir barracos improvisados para se abrigar. Neste caso, os interesses dos agricultores convergem com aqueles das empresas de fornecimento de eletricidade, para quem as moradias precárias representam mais riscos do que as hortas.

No campo das diferentes perspectivas agroalimentares para o desenvolvimento territorial da Zona Leste de São Paulo, dois projetos distintos de agricultura urbana rivalizam-se. De um lado, a ONG Cidade Sem Fome defende um modelo agrícola produtivista ancorado em justificativa industrial, ainda que sustentado por uma perspectiva de abastecimento alimentar, e, de outra parte, agricultores ligados notadamente à AAZL desenvolvem uma resposta ao problema de segurança alimentar com uma atividade agrícola diversificada e respeitosa do meio ambiente, tendendo a mobilizar em suas justificativas princípios de justiça cívicos e ecológicos.

Para o fortalecimento desta última orientação, os entrevistados acreditam que seria necessária uma sensibilização das autoridades municipais em termos do reconhecimento da importância estratégica multidimensional da agricultura urbana. De fato, a legislação municipal refere-se pouco à AUP e ao abastecimento alimentar. Ademais, o conhecimento dos diferentes papéis das atividades agrícolas no município é bastante limitado, o que é explicado em certa medida pela grande compartimentalização da administração municipal.

Para o cumprimento efetivo dos múltiplos papéis sociais, ambientais, econômicos e alimentares da AUP, é evidente que os desafios são diversos. Em termos de segurança alimentar, a distribuição dos alimentos produzidos pelos membros da AAZL sofre da precariedade da infraestrutura logística. Assim, a ausência de veículo próprio e os custos de frete constituem um freio maior para o desenvolvimento desta agricultura urbana. Por outro lado, a superação das barreiras 
para a realização de uma maior reciclagem de recursos para a produção (sobretudo água e matéria orgânica), representando o cumprimento de uma função ecológica desta agricultura, exige esforços consideráveis.

Quanto ao assentamento Milton Santos, as interrogações sobre o desenvolvimento territorial e sobre o acesso à terra levam imediatamente suas lideranças a salientar a insuficiência da intervenção do INCRA, cuja promessa inicial de instalar as famílias sem terra em parcelas de 3 a 4 ha não foi cumprida. Apesar de tudo, os assentados exprimem o desejo de provar que, mesmo com pouca terra disponível para cultivo, é possível produzir com criatividade, a partir de uma orientação agroecológica e uma sólida organização social, o que asseguraria uma renda decente para as famílias. Os esforços para fortalecer a cooperativa local inscrevem-se nesta perspectiva.

Por outro lado, um problema maior destacado pelos entrevistados diz respeito à concorrência entre projetos para o desenvolvimento do território, opondo a produção agroecológica de alimentos das famílias assentadas contra a monocultura industrial canavieira, que ocupa praticamente todas as cercanias do assentamento. Assim, o cultivo orgânico das famílias assentadas encontra limites associados ao estado de degradação do solo, causado pelo seu uso intensivo anterior à implantação do assentamento. Ademais, o uso frequente de agrotóxicos por meio de aviação agrícola contamina seriamente a produção orgânica, quando não provoca intoxicação dos assentados. Este tipo de crítica apoia-se em princípios de justiça doméstica (em termos de proteção da família), cívica (em razão da participação em ação coletiva para alcançar bem-estar social) e ecológica (no que se refere ao respeito do meio ambiente) contra uma orientação agrícola fundada em ordem justa industrial-mercantil, que valoriza antes de tudo lucratividade e eficácia da máquina produtiva (Boltanski \& Thévenot, 1991; Moruzzi Marques et al., 2016; Retière \& Moruzzi Marques, 2019).

Enfim, o desenvolvimento deste território deverá adequar-se ao Plano Diretor de Desenvolvimento Físico Urbanístico do município de Americana, mais especificamente à regulamentação da Macrozona de Uso Predominantemente Ambiental, cuja elaboração estava em curso no momento da pesquisa de campo. A participação dos assentados neste processo ocorre de maneira indireta, por meio de vereadores com posições próximas aos interesses das famílias assentadas ou dispostos a defender suas reivindicações. Desta forma, a direção local do MST parece aceitar em parte a proposta, muito disseminada, de aumentar a densidade demográfica das terras vizinhas ao assentamento ("o que é melhor do que a monocultura de cana", como menciona um dirigente do movimento local). Porém, esta orientação favorável à urbanização não deveria significar um bloqueio para a produção agrícola local, voltada ao fornecimento de alimentos para moradores das redondezas. Assim, seria desejável, segundo os termos da dirigente local do MST entrevistada, que os novos residentes pudessem ter ao menos uma área para cultivo de seus próprios alimentos.

\section{Estratégias priorizadas}

Após este quadro de ações e concepções de atores da AUP, convém agora examinar as estratégias para perenizar suas atividades agrícolas. No caso do município de São Paulo, a mobilização de coletivos urbanos favoráveis à agricultura, de forma coerente com uma perspectiva cívica de justiça, demanda sustentação dos poderes públicos, contribuindo para conferir visibilidade e legitimidade à AUP. Assim, como anteriormente mencionado, uma zona rural, no sul do município, foi demarcada quando da elaboração do Plano Diretor e, de outra parte, o Plano Municipal de Agroecologia e Desenvolvimento Rural Sustentável e 
Solidário (PMADRSS) foi concebido por ocasião da revisão das diretrizes estratégicas para o desenvolvimento municipal. A implantação deste último plano é considerada pelos atores da AUP como o resultado mais significativo da referida mobilização.

A propósito da zona rural do município de São Paulo, sua ocupação é fonte de muitas tensões entre diferentes projetos de grupos sociais específicos. A informante entrevistada da Secretaria Municipal de Desenvolvimento Urbano revelou que os poderes públicos encontram muitas dificuldades nas negociações sobre o uso destas áreas rurais. Efetivamente, os dispositivos tradicionais de planejamento urbano não integram abordagens para o tratamento de atividades agrícolas. De todo modo, a delimitação de uma zona rural no município de São Paulo constitui um avanço considerável para o reconhecimento da AUP, permitindo apoiar oficialmente as atividades agrícolas com ações públicas municipais. De fato, a designação "rural" permite aos atores da AUP legitimar suas atividades agrícolas. Contudo, convém realçar que parte preponderante das políticas de desenvolvimento rural (assistência técnica, crédito rural e reforma agrária) são atribuições dos estados e da União, mesmo que as reivindicações dos agricultores sejam canalizadas ao governo municipal, o que aliás induz a um desequilíbrio entre as demandas da AUP e as possibilidades de atendimento da administração municipal.

De toda maneira, o reforço da agricultura urbana ocorre também graças à participação de representantes da AAZL nos conselhos municipais, particularmente no CMDRSS, e também nas audiências públicas quando do processo de elaboração do novo PDE, em 2014. Com esta estratégia ancorada em princípios cívicos de justiça, a associação participou igualmente dos debates relativos à preparação do PDRSS.

Quanto ao outro caso estudado, o processo de elaboração do Plano Diretor do município de Americana oferece elementos instigantes para discutir as estratégias dos atores implicados. Este plano é previsto no Estatuto da Cidade (Lei $n^{\circ} 10.257$ de 2001) como um instrumento fundamental da política de desenvolvimento urbano. Para sua construção, são previstos debates e audiências públicas com a participação da população e das associações representativas de diferentes segmentos da sociedade local.

Em tal plano em Americana, homologado em 2018 (Lei $n^{\circ}$ 6.264), foi estabelecido uma "macrozona de uso predominantemente ambiental", para o território no qual se situa o assentamento Milton Santos. Os representantes locais do MST escolheram abster-se da participação direta nas consultas públicas. Neste âmbito das disputas em torno do desenvolvimento territorial, sua estratégia focaliza o confronto contra a produção industrial canavieira, em particular reivindicando a proibição de pulverização aérea no município de Americana. A propósito, o vereador Sergio Fioravante Alvarez apresentou o Projeto de Lei (PL) n 53/2017, proibindo a pulverização aérea de agrotóxicos no âmbito do município de Americana. Entre seus argumentos, este membro da câmara legislativa local salienta que os produtores do "assentamento Milton Santos correm o risco de perderem o selo de produção orgânica devido aos agrotóxicos que são pulverizados na área, [...] estão preocupados com a constante pulverização nas plantações de cana-de-açúcar que circundam o assentamento". Sua argumentação não permitiu convencer a maioria de seus pares, pois este PL foi indeferido por nove votos contrários, diante de oito vereadores favoráveis.

Quanto à regulamentação do Plano Diretor, a vereadora entrevistada desta Câmara Municipal considerou que a nova legislação deveria impedir a autorização de loteamentos com pequenas parcelas (menores que $150 \mathrm{~m}^{2}$ ) na macrozona de uso predominantemente ambiental, o que evitaria seu uso estritamente residencial e permitiria preservar o caráter de proteção do meio ambiente desta área. Em todo caso, a tendência era, quando da realização da pesquisa de campo, formalizar uma legislação de ocupação do solo muito permissiva, atendendo aos interesses de 
grandes promotores imobiliários. Assim, a preservação ambiental desta subzona se limitaria às margens da represa do Salto Grande, cuja degradação contribuiu com a concepção da proposta de delimitar uma macrozona destinada à proteção do meio ambiente. Neste caso, a promoção da AUP seria negligenciada na Macrozona de Uso Predominantemente Ambiental.

A estratégia defensiva dos representantes do assentamento Milton Santos orienta-se pela legitimação do projeto local de produção ecológica e de comercialização solidária. Nesta ótica, buscam deslegitimar as empresas cujos planos e lógicas são considerados prejudiciais para a atividade agrícola das famílias assentadas. Trata-se de uma estratégia coerente com um regime doméstico/ecológico de justiça, ao favorecer redes locais solidárias de consumo de produtos orgânicos fundadas em confiança mútua. A Cooperflora constitui uma peça chave desta linha estratégica, representando o meio pelo qual são oferecidas condições de produção e comercialização via grupos de consumo solidário, o que pressupõe solidariedade entre os próprios assentados, representada pela cooperativa e pelas organizações locais de controle social.

As estratégias das famílias assentadas visando legitimar suas atividades apoiam-se igualmente em princípios cívicos/ecológicos de justiça, como se constata no caso de sua ação coletiva em relação ao aterro sanitário instalado próximo ao assentamento. A administração deste empreendimento deseja que os resíduos sólidos de outros municípios possam ser importados para Americana, tornando a empresa mais rentável. Para tal procedimento, a legislação municipal obriga esta última a promover compensações ambientais. Assim, a empresa em questão exprimia seu interesse em apoiar o reflorestamento de áreas protegidas do assentamento. Todavia, os assentados em decisão coletiva votada em assembleia recusaram tal apoio, evidenciando o desacordo com os propósitos de ampliação do aterro, o que poderia se tornar uma ameaça à agricultura orgânica local.

\section{Conclusão}

Como destacado por Lardon et al. (2016), objetos espaciais integradores, tal como a alimentação, constituem eixos em torno dos quais atores se apropriam de uma visão prospectiva do território. O potencial criativo desta apropriação permite ampliar o campo das possibilidades em torno da agricultura urbana e periurbana. Nesta ótica, constata-se que os projetos de AUP tal como compreendidos por diferentes coletivos territoriais não se esgotam em suas finalidades imediatas, mas se inscrevem, de diferentes maneiras, em perspectivas potencialmente mais globais.

Com este olhar analítico, nos campos de debates e de embates analisados, destaca-se que a promoção do crescimento urbano é considerada como crucial para o desenvolvimento territorial pela maior parte dos agentes econômicos e das autoridades municipais de Americana e que o movimento de moradia de São Paulo reivindica terrenos para edificação. Em ambos os casos, a agricultura urbana concorre em desvantagem com estas pujantes demandas socioeconômicas. Tanto o assentamento Milton Santos quanto a AAZL enfrentam este tipo de competição em torno do acesso à terra.

Nos fóruns de tomada de decisão em torno do planejamento municipal, a participação dos atores da AUP é limitada. Assim, suas estratégias concentram-se na busca de legitimidade para uma produção de qualidade, que permita criar redes de solidariedade em torno dos esforços para desenvolver uma agricultura ecológica. Este tipo de produção permite obter uma alimentação saudável, ao mesmo tempo em que representa a possibilidade de realização 
de uma atividade prazerosa, como mencionado por entrevistados da AAZL. É assim que estes atores consideram inadequado e injusto avaliar suas atividades em termos de produtividade.

Neste quadro, a abordagem da sociologia das justificações é bastante instigante por permitir evidenciar os pontos de ancoragem normativa de justiça das perspectivas em torno da AUP. A defesa desta última mobiliza diferentes conjuntos de referências de ordenamento de um mundo justo situados notadamente nos regimes de justiça cívicos, domésticos e ecológicos que se opõem particularmente à orientação industrial de justiça. Trata-se de assegurar direitos através da participação em coletivos (ordem justa cívica), como associações e cooperativas, com o objetivo de garantir uma utilização agroecológica (ordem justa ecológica) de bens públicos. A valorização da proximidade entre agricultores e consumidores configura uma estratégia de implantação de redes de solidariedade fundadas em relações de confiança interpessoal (ordem justa doméstica).

Convém insistir que um elemento compartilhado por entrevistados dos dois casos estudados refere-se à centralidade da questão fundiária. Deste modo, é possível conceber que o acesso à terra, cujo direito é justificado principalmente por regimes de justiça cívicos, domésticos e ecológicos, constitui um tema de construção de alianças, mas também de eclosão de futuros conflitos. Tal horizonte mostra igualmente a importância de uma leitura com ótica transversal da AUP, pois o compartilhamento do solo com diversos objetivos e a coabitação entre diferentes práticas espaciais levantam um problema de natureza integradora.

De todo modo, a defesa do direito de acesso à terra para produzir alimentos diante daquela do direito à moradia provoca tensões, constituindo um desafio central para a AUP. A ambição de alcançar uma sustentabilidade que possa ser efetivamente inclusiva requer a integração profunda das dimensões ambientais e sociais aos planos de desenvolvimento. Desta maneira, os múltiplos papéis da agricultura urbana e periurbana poderiam constituir um trunfo para seu reconhecimento e fortalecimento.

\section{Bibliografia}

Aly Junior, O. (2011). Projetos de Desenvolvimento Sustentável (PDS) e os desafios na construção de novas políticas de assentamento. Retratos de Assentamentos, 14(2), 283-304.

Biazoti, A. R. (2020). Engajamento político na agricultura urbana: a potência de agir nas hortas comunitárias de São Paulo (Dissertação de mestrado). Ecologia Aplicada Universidade de São Paulo, Piracicaba. http://dx.doi.org/10.11606/D.91.2020.tde-09032020-170856.

Boltanski, L. (1990). L'amour et la justice comme compétences. Paris: Gallimard.

Boltanski, L., \& Thévenot, L. (1991). De la justification. Paris: Gallimard.

Borsatto, R., \& Carmo, M. S. (2013). A construção do discurso agroecológico no Movimento dos Trabalhadores Rurais Sem-Terra (MST). Revista de Economia e Sociologia Rural, 51(4), 645-660. http://dx.doi.org/10.1590/S0103-20032013000400002

Caldas, E. L., \& Jayo, M. (2019). Agriculturas urbanas em São Paulo: histórico e tipologia. Confins, 39; http://dx.doi.org/10.4000/confins.18639

Capel, H. (2002). La morfología de las ciudades. Tomo I. Sociedad, cultura y paisaje urbano. Barcelona: Ediciones del Serbal.

Carvalho, L., \& Bógus, C. M. (2020). Gender and social justice in urban agriculture: the network of agroecological and peripheral female urban farmers from São Paulo. Social Sciences, 9(8), 127. http://dx.doi.org/10.3390/socsci9080127

Castells, M. (1974). La question urbaine. Paris: Maspero. 
Chiaramonte Pires, V. (2016). Agricultura Urbana como fator de desenvolvimento sustentável: Um estudo na Região Metropolitana de Maringá. Revista Pesquisa \& Debate, 27(2), 70-84.

Curan, R. M. (2020). Multifuncionalidade da agricultura urbana de base agroecológica: um estudo na Zona Leste do município de São Paulo/SP (Dissertação de Mestrado). Ecologia Aplicada, Universidade de São Paulo, Piracicaba.

Dematteis, G. (2005). Geografia Democrática, território e desenvolvimento local. Formação, 12(2), 11-26.

Favareto, A. S. (2007). A longa evolução da relação rural-urbano. Ruris, 1(1), 157-192.

Food and Agriculture Organization of the United Nations - FAO. Fighting Poverty and Hunger: Economic and Social Perspectives. Rome, Italy: FAO; 2010. (Policy Brief, 10). Recuperado em 10 de outubro de 2018, from http://www.fao.org/docrep/012/al377e/al377e00.pdf.

Georges, P. (1981). Géographie des inégalités. Paris: Presses Universitaires de France.

Giacchè, G. (2015). Políticas públicas de agricultura urbana e periurbana: uma comparação entre os casos de São Paulo e Campinas. Informações Econômicas, 45(6), 45-60.

Gottlieb, R., \& Joshi, A. (2010). Food justice. Cambridge: MIT Press.

Greffe, X. (2002). Le développement local. Paris: Editions de l'Aube.

Guiraud, N., Laperriere, V., \& Rouchier, J. (2014). Une géographie des circuits courts en région Provence-Alpes-Côte d'azur. État des lieux et potentialités de développement. L'Espace Geographique, 43(4), 356-373.

Harvey, D. (2005). A produção capitalista do espaço. São Paulo: Annablume.

Jacquemain, M. (2001). Les cités et les mondes: le modèle de la justification chez Boltanski et Thevenot. Département de sciences sociales, Université de Liège, Belgica.

Kay, S., Mattheisen, E., McKeon, N., De Meo, P., \& Moragues Faus, A. (2018). Public Policies for Food Sovereignty (Think piece series Food for Thought, 1). Amsterdam, Rome and Heidelberg: TNI. Recuperado em 10 de outubro de 2018, from http://www.fian.org/fileadmin/media/ publications_2018/Reports_and_guidelines/web_public_pol_food_sov.pdf

Lacoste, Y. (1976). La géographie, ça sert, d'abord, à faire la guerre. Paris: Maspero.

Lafaye, C., \& Thévenot, L. (1993). Une justification écologique? Revue Française de Sociologie, 34(4), 495-524.

Lahire, B. (2013). Dans les plis singuliers du social: individus, institutions, socialisations. Paris: Éditions La Découverte.

Lamine, C., Renting, H., Rossi, A., Wiskerke, J. S. C., \& Brunori, G. (2012). Agri-food systems and territorial development: innovations, new dynamics and changing governance mechanisms. In I. Darnhofer, D. Gibbon \& B. Dedieu (Eds.), Farming systems research into the 21st century: the new dynamic (pp. 229-256). Berlin: Springer.

Lardon, S., Marraccini, E., Filippini, R., Gennai-Schott, S., Johany, F., \& Rizzo, D. (2016). Prospective participative pour la zone urbaine de Pise (Italie): I'eau et l'alimentation comme enjeux de développement territorial. Cahiers de Geographie de Quebec, 60(170), 265-286.

Lardon, S., Houdart, M., Loudiyi, S., Filippini, R., \& Marraccini, E. (2017). Food, Integrating Urban and Agricultural Dynamics in Pisa, Italy, In C. Soulard, C. Perrin \& E. Valette (Eds.). Toward sustainable relations between agriculture and the city (pp. 15-31).Berlin: Springer.

Latour, B. (1995). Moderniser ou écologiser? A la recherche de la septième cité. Ecologie politique, (13), 5-27. 
Leão, V. O. P. S. (2019). Organizações de Controle Social na Região Metropolitana de São Paulo: relações de proximidade e de confiança em foco (Dissertação de mestrado). Ecologia Aplicada, Universidade de São Paulo, Piracicaba. http://dx.doi.org/10.11606/D.91.2019.tde-19112019123542.

Lefebvre, H. (1974). La production de l'espace. Paris: Anthropos.

Madaleno, I. M. (2002). A cidade das mangueiras: agricultura urbana em Belém do Pará. Lisboa: Fundação Calouste Gulbenkian.

McCarthy, J. D., \& Zald, M. N. (1977). Resource mobilization and social movements. American Journal of Sociology, 82(6), 1212-1241.

Mello Pinto, S., \& Moruzzi Marques, P. E. (2019). Redução do apoio público aos assentamentos: análise de uma resposta fundada em consumo solidário no assentamento Milton Santos. Retratos de Assentamentos, 22(2), 131-146.

Moragues-Faus, A. (2017). Problematising justice definitions in public food security debates: Towards global and participative food justices. Geoforum, 84, 95-106.

Morgan, K. (2009). Feeding the city: The challenge of urban food planning. International Planning Studies, 14(4), 341-348.

Moruzzi Marques, P. E. (2014). Críticas e justificações em torno de alternativas agrícolas no estado de São Paulo (Tese de livre docência). Escola Superior de Agricultura Luiz de Queiroz, Universidade de São Paulo, São Paulo. http://dx.doi.org/10.11606/T.11.2014.tde-17092014084108.

Moruzzi Marques, P. E., Lucas, A., \& Gaspari, L. (2014). Desenvolvimento territorial em questão: estudo sobre assentamento periurbano no estado de São Paulo. Retratos de Assentamentos, 17(1), 161-178.

Moruzzi Marques, P.E., \& Moal, M. (2014). Le Programme d'Acquisition d'Aliments (PAA) au Brésil: I' agriculture locale et familiale au coeur de I'action publique en vue de la sécurité alimentaire. VertigO: La Revue Electronique en Sciences de L'environnement, 14, 1-18.

Moruzzi Marques, P. E., Khatounian, C. A., Gaspari, L. C., \& Retiere, M. (2016). Justificações em torno de assentamento periurbano da modalidade PDS no estado de São Paulo: uma justiça ecológica em questão. Retratos de Assentamentos, 19(1), 21-40.

Moruzzi Marques, P. E., Gaspari, L. C., \& Almeida, B. (2017). Organização de Controle Social (OCS) e engajamento agroecológico das famílias do assentamento Milton Santos no estado de São Paulo. Estudos Sociedade e Agricultura, 25(3), 545-560. http://dx.doi.org/10.36920/esa-v25n3-4

Mougeot, L. J. A. (2000). Urban Agriculture: definition, presence, potentials and risks. In: N. Bakker, M. Dubbeling, S. Guendel, U. Sabel Koschella, \& H. De Zeeuw (Eds.). Growing Cities, Growing Food, Urban Agriculture on the Policy Agenda. Feldafing, Germany: Deutsche Stiftung fur internationale Entwicklung (DSE).

Nahmias, P. \& Le Caro, Y. (2012). Pour une définition de l'agriculture urbaine: réciprocité fonctionnelle et diversité des formes spatiales. Environnement urbain, 6, a1-a16.

Neves, E., Barbosa, M. J., Matos, A., Oliveira, G., \& Santana, S. (2010). Contribuição do centro de agricultura urbana e periurbana da região metropolitana de Belém para a segurança alimentar em assentamento periurbano. Brazilian Journal of. Food Technoly. 13, 27-33. http://dx.doi. org/10.4260/BJFT20101304105.

Opitz, I., Berges, R., Piorr, A., \& Krikser, T. (2015). Contributing to food security in urban areas: differences between urban agriculture and peri-urban agriculture in the Global North. Agriculture and Human Values, 33, 341-358. 
Peemans, J.-Ph. (Dir.) (2008). Territoire, développement et mondialisation. Paris, Louvain-la-Neuve: Alternatives Sud.

Pessoa, C. C., Souza, M., \& Schuch, I. (2006). Agricultura Urbana e Segurança Alimentar: um estudo no município de Santa Maria/RS. Segurança Alimentar e Nutricional, Campinas, 13(1), 23-27.

Raffestin, C. (1993). Por uma geografia do poder. São Paulo: Editora Ática.

Resources Centres on Urban Agriculture \& Food Security Foundation - RUAF. (2018). Urban agriculture: what and why? Recuperado em 10 de outubro de 2018 de http://www.ruaf.org/ urban-agriculture-what-and-why

Retière, M., \& Moruzzi Marques, P. E. (2019). A justiça ecológica em processos de reconfiguração do rural: estudo de casos de neorrurais no estado de São Paulo. Revista de Economia e Sociologia Rural, 57(3), 490-503. http://dx.doi.org/10.1590/1806-9479.2019.184109

Rich, K., Rich, M., \& Dizyee, K. (2016). Participatory systems approaches for urban and periurban agriculture planning: The role of system dynamics and spatial group model building. Agricultural Systems, 160, 110-123.

Sanchez-Hernandez, J. L., \& Moro-Gutierrez, L. (2019). Los órdenes de justificación como marco analítico para el estudio de las prácticas económicas alternativas. Reis -. Revista Espanola de Investigaciones Sociologicas, 167, 107-124.

Santandreu, A., \& Lovo, I. C. (2007). Panorama da agricultura urbana e periurbana no Brasil e diretrizes políticas para sua promoção. Identificação e Caracterização de Iniciativas de AUP em Regiões Metropolitanas Brasileiras. Belo Horizonte: FAO/ONU e DPSD/SESAN/MDS.

Santos, M. (1994). Território globalização e fragmentação. São Paulo: Hucitec.

Tilly, C., \& Tarrow, S. (2008). Politique(s) du conflit. Paris: Presses de Sciences Po.

Thompson, J., \& Scoones, I. (2009). Addressing the dynamics of agri-food systems: An emerging agenda for social science research. Environmental Science \& Policy, 12(4), 386-397.

Torres, H., Alves, H., \& Oliveira, M. A. (2007). São Paulo peri-urban dynamics: Some social causes and environmental consequences. Environment and Urbanization, 19(1), 207-223.

Trauger, A. (2015). Food sovereignty in international context: discourse, politics and practice of place. Londres: Routledge.

Travassos, L., \& Portes, B. (2018). Rural metropolitano: caracterização e regulação na Região Metropolitana de São Paulo (Brasil). Revista de Geografia e Ordenamento do Território, 14, 359-380. https://dx.doi.org/10.17127/got/2018.14.015.

Van Dam, D., \& Nizet, J. (2012). Les agriculteurs bio deviennent-ils moins bio? In D. Van Dam, P. Stassart, J. Nizet, \& M. Streith. Agroécologie: Entre pratiques et sciences sociales. Dijon: Educagri.

Van Veenhuizen, R. (2006). Cities Farming for the Future. In R. Van Veenhuizen (Ed.). Cities Farming for the Future: Urban agriculture for green and productive cities. Canada, RUAF Foundation, IDRC \& IIRR.

Wald, N., \& Hill, D. (2015). Rescaling' alternative food systems: From food security to food sovereignty. Agriculture and Human Values, 33(1), 203-213.

Wiskerke, J. S. C. (2010). On places lost and places regained: reflections on the alternative food geography and sustainable regional development. International Planning Studies, 14(4), 369-387. 